\title{
O freio labial superior e sua influência no diastema mediano superior
}

\author{
José Renato Prietsch* \\ Elizabeth Bernst Justo** \\ Eduardo Martinelll de Lima***
}

\begin{abstract}
RESUMO
Ao analisarmos os diversos agentes etiológicos do diastema mediano superior, foi encontrado, por eliminaçăo destes agentes, que o freio é apenas uma entre as várias causas de diastema.

Este freio é chamado de freio teto labial persistente.

Um roteiro espećfico para diagnóstico do freio patológico foi elaborado, tendo por base a cronologia de desenvolvimento e características físico-clínicas associadas a diferentes imagens radiográficas de suturas palatinas medianas.
\end{abstract}

\section{SUMMARY}

After analyzing the several etiological agents of the upper median diastema, it was possible to find by mean of elimination of these agents that the frenum is only one of the several causes of diastema.

This frenum is called persistent tectolabial frenum.

A specific route was elaborated for the diagnosis of the pathological frenum. This diagnosis is based on the chronology of development and on physical and clinical characteristics that are associated to different images of radiographs of

intermaxillary sutures.

\section{DESCRITORES}

Freio teto-labial persisitente. Diastema mediano superior. Sutura palatina mediana. Fibras Transeptais. Papila palatina.

Papila interincisal

\section{INTRODUÇÃO}

Não há dúvida de que um autêntico freio anormal seja capaz de manter uma separaçăo entre os incisivos centrais superiores; porém, há uma certa generalização entre os clínicos de que o freio labial superior seja o principal agente etiológico do diastema mediano superior.

O propósito deste artigo é o de localizar - problema diastema mediano superior em seu contexto real dentro do planejamento do tratamento ortodóntico, bem como examinar a relaçảo dos diferentes tipos de freios labiais superiores com o diastema mediano.

\section{FREIO TETO LABIAL}

Embriologicamente o freio labial superior parece se desenvolver do processo frontonasal e começa a tomar forma, no feto, em um estágio relativamente cedo. Em poucos meses de vida fetal ele emerge como parte da cavidade oral junto com o lábio e face.

Com o progresso do crescimento desenvolvimento, a proeminência começa a aparecer na parte da linha média, no interior da zona do lábio superior, começando a formação do tubérculo.

Durante este processo, outra proeminência se forma parte anterior do palato, constituindo a papina palatina.

Uma contínua dobra de tecido, o freio teto labial, conecta o tubérculo com a pa- pila palatina. É interessante notar que o freio teto labial do feto simula o freio anormal da vida pós-natal.

O freio teto labial se extende como uma faixa contínua de tecido, indo para o interior do lábio superior, para cima e através da crista alveolar para ser inserido na papila palatina $(01,05,07,18,19)$, Fig 1 .

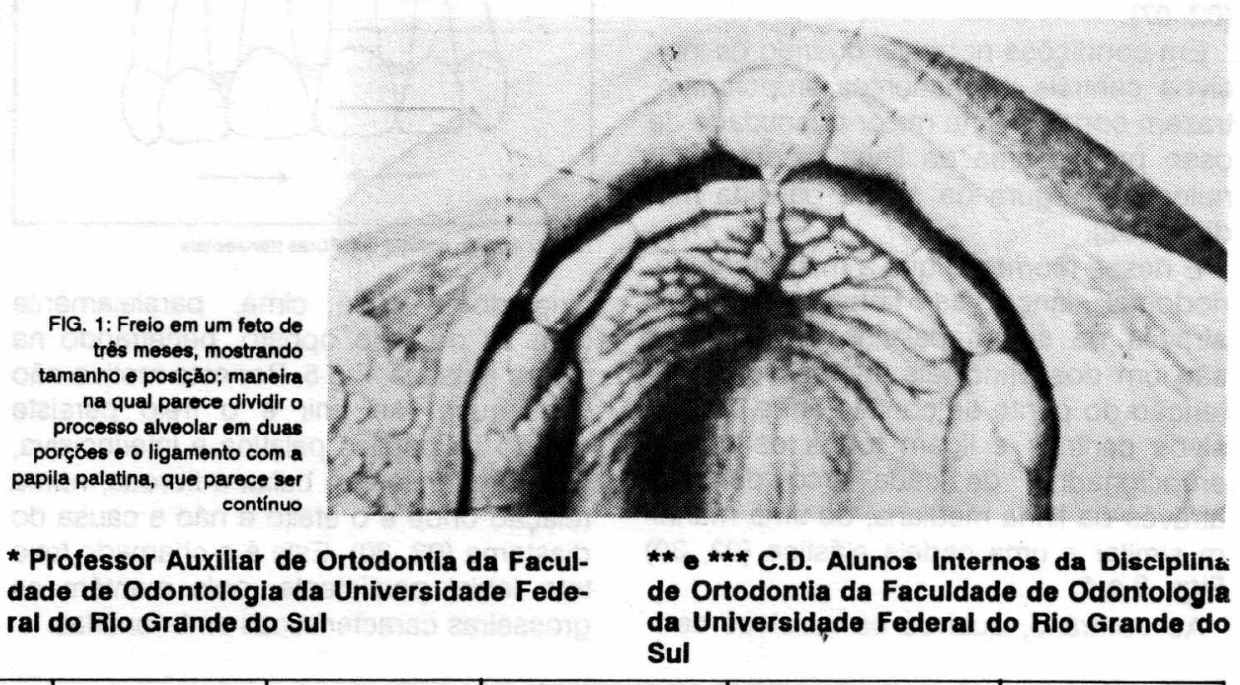

R. Fac. Odontol.

Porto Alegre

V. 32

N. 2

p.9-14

NOVEMBRO

1991 
Mas, segundo Orban, o crescimento do processo alveolar (para baixo e para frente), excede o do freio, fazendo com que já ao nascimento exista uma soluçāo de continuidade neste tecido, dividindo-o entre palato e porçāo labial. A parte palatal corresponde a papila palatina e o tecido labial se transforma em freio labial superior, extendendo-se do lábio à crista do processo alveolar (19) Fig. 2. trais erupcionam amplamente separados um do outro e a cinta óssea que os envolve năo for suficiente para diminuir a sutura palatina, nāo será depositado osso imediatamente inferior ao freio, que se manterá na crista da margem gengival. Nestas condiçőes, devido a grande distância, as fibras transeptais ficam impedidas de passar de um lado a outro da linha média e mudam seu trajeto em $90^{\circ}$,

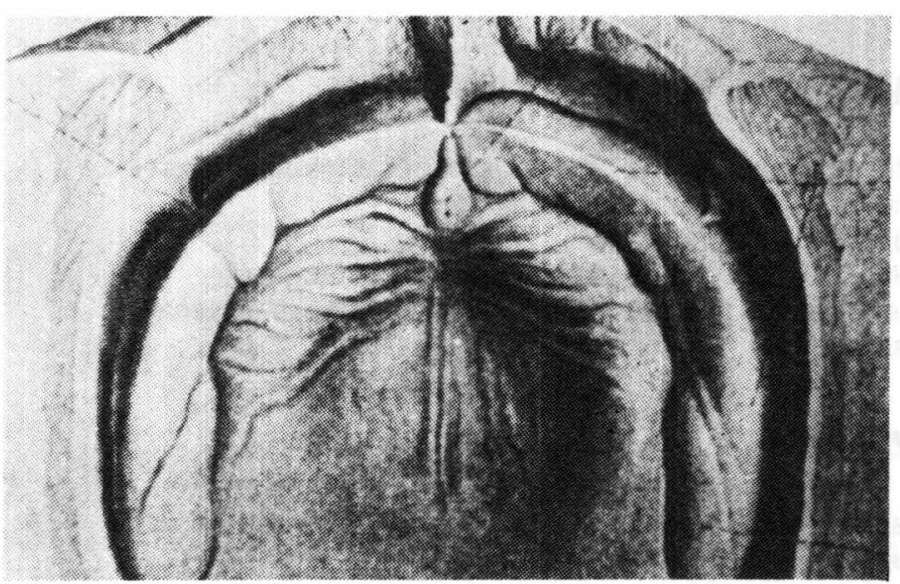

FIG. 2: Criança recém nascida Já existe uma solução de continuidade entre freio labial superior e papila palatina

Os surtos de crescimento durante a erupçāo dos incisivos temporários e permanentes vão distanciar ainda mais a inserçāo do freio, fazendo com que este assuma uma posiçāo normal acima da crista alveolar em cerca de $4 \mathrm{~mm}$.

Certos fatores podem permitir que o freio fique unido a papila palatina.

Para explicarmos melhor este processo, devemos nos lembrar que o desenvolvimento alveolar antecede a erupçăo dental e a presença dos incisivos centrais temporários tem produzido o espaço de desenvolvimento para os dentes permanentes, que săo maiores. Também nāo podemos esquecer que os incisivos centrais superiores, ao contrário dos outros dentes, desenvolvem-se em criptas ósseas separadas pela sutura palatina mediana $(02,07)$.

Em condiçōes normais, quando os incisivos centrais permanentes erupcionam, trazem consigo uma maior quantidade de osso para a área da linha média, diminuindo a largura da sutura palatina mediana (02).

É nesse momento que a membrana periodontal lança as fibras transeptais através da sutura palatina. Estas fibras săo um dos principais fatores de manutenção do ponto de contato entre os incisivos centrais e ligam todos os dentes erupcionados, de cada arco dentário, através da linha mediana, de uma maneira similar a uma cadeia elástica $(02,30)$ Figs. 3 e 4.

Ao contrário, quando os incisivos cen-

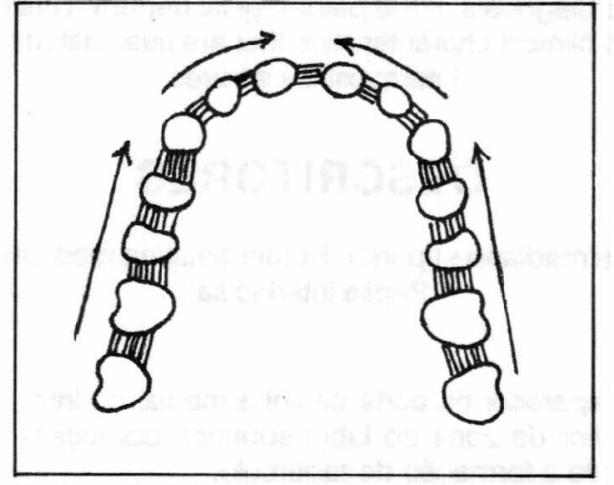

FIG. 3: Cadeia elástica representando os dentes ligados por fibras transeptais periodontais

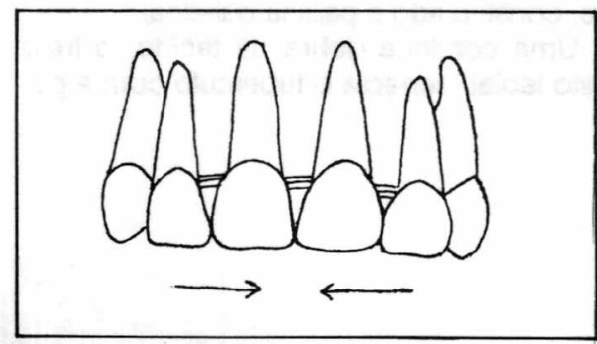

FIG. 4: Arranjo normal des fibras transeptais

dirigindo-se para cima, paralelamente com as do lado oposto, penetrando na sutura palatina. Fig 5. Por este motivo nảo conseguem se unir e o freio persiste unindo as papilas palatina $\theta$ interincisiva, com uma inserçāo baixa e fibrosa, numa relaçăo onde é o efeito e nāo a causa do diastema $(02,30)$. Este é o chamado freio teto labial persistente, pois mantém as grosseiras características embrionárias.

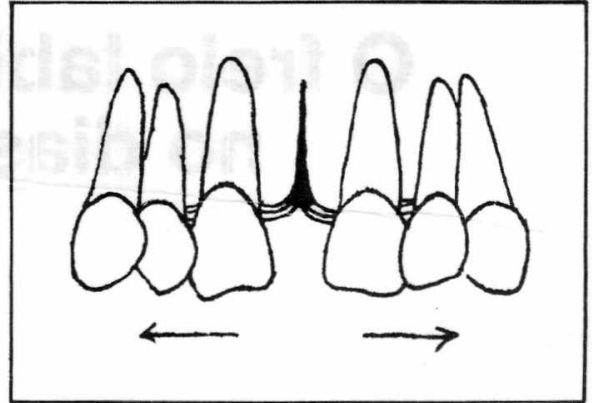

FIG. 5: Fibras transeptais invaginadas para dentro da sutura palatina mediana. Influência das fibras transeptais na formação e posição do diastema

\section{ETIOLOGIA DO DIASTEMA MEDIANO}

\section{NORMAL}

1.a. Desenvolvimento: na presença de um diastema mediano superior, devemos avaliar as diversas causas possíveis antes de relacioná-lo com o freio labial, pois ele pode estar simplesmente representando uma fase do desenvolvimento da dentiçăo.

Segundo Broadbent, os incisivos centrais permanentes, quando erupcionam, têm uma inserção distal com coroas divergentes. Isso é causado pela proximidade das coroas dos caninos com as raízes dos incisivos laterais. A medida que os caninos irrompem, as raízes dos incisivos permanentes migram para a área antes ocupada pelas coroas dos caninos, assumindo uma posiçāo mais vertical, fazendo com que as coroas dos incisivos laterais entrem em contato com as coroas dos incisivos centrais, reduzindo o diastema mediano. $(02,04,05,07,08)$. Fig. 6

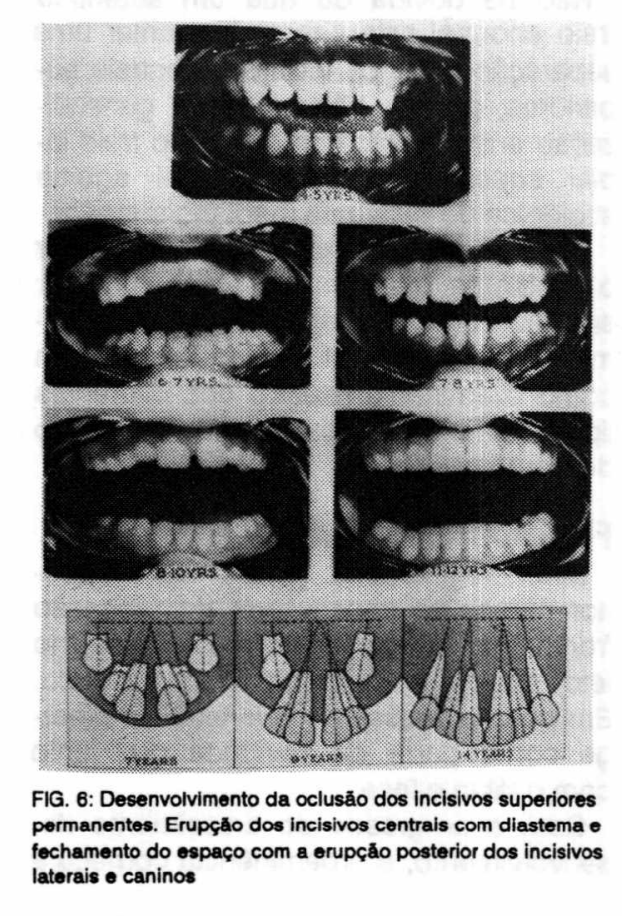

FIG. 6: Desenvolvimento da oclusăo dos incisivos superiores permanentes. Erupçăo dos incisivos centrais com diastema e fechamento do espaço com a erupção posterior dos incisivos laterais e caninos

\section{R. Fac. Odontol.}

Porto Alegre

\begin{abstract}
v. 32
\end{abstract}

N. 2


Este processo foi corroborado por outros pesquisadores como Taylor (32) que, em 1939, relacionando a presença do diastema com a idade, observou que existe uma tendência de diminuir a incidência do diastema com o passar do tempo. Encontrou uma incidência de $\mathbf{9 7 \%}$ aos 6 anos, baixando para $88 \%$ aos 7 anos. Em criança de 10 anos encontrou $49 \%$, caindo para $7 \%$ a partir dos 12 anos. $(32,35)$. Tabela 1.

TABELA I

Incidência do diastema mediano superior em diferentes faixas etárias, segundo Taylor

\begin{tabular}{ccc}
\hline \multicolumn{3}{c}{$\begin{array}{c}\text { TAYLOR; 1939 } \\
\text { Am. J. Orthod }\end{array}$} \\
\hline $\begin{array}{c}\text { Idade } \\
\text { (anos) }\end{array}$ & $\begin{array}{c}\text { Número } \\
\text { de casos }\end{array}$ & Porcentagem \\
\hline 6 & 66 em 68 & 97 \\
$6-7$ & 29 em 33 & 88 \\
$10-11$ & 18 em 37 & 49 \\
$12-18$ & 75 em 1067 & 7 \\
\hline
\end{tabular}

Weimann (36), em 1967, relacionou a presença do diastema com o estágio de erupçảo dentária e observou que a incidência do diastema diminui a medida que erupcionam os incisivos laterais $\theta$ caninos permanentes.

Segundo Broadbent (4), esta fase onde a presença do diastema faz parte do desenvolvimento normal do ser humano $e ́$ chamada fase do "patinho feio". Assim sendo, um freio que parece anormal aos 6 anos pode parecer normal aos 12 anos.

1.b. Étnico e Familiar: certos grupos de pessoas, particularmente negróides e grupos mediterrâneos exibem um diastema mediano como forma étnica. $(02,35)$.

É freqüentemente associado a vários graus de protrusāo maxilar que tende a aumentar o comprimento do arco alveolar, possibilitando maior espaço para os dentes.

\section{DEFICIÊNCIA DE MATERIAL DENTÁRIO NO ARCO}

2.a. Dentição espaçada: nestes casos, 0 comprimento do arco é sempre maior que a soma da largura mésio distal dos dentes naquele arco. Os dentes são mais ou menos uniformemente espalhados pelas arcadas com espaços bastante semeIhantes entre todos eles, exceto na regiăo molar, onde os contato estāo quase sempre presentes.

Porém, também podemos encontrar este espaço concentrado na linha mediana, formando um diastema único. (02).

2.b. Dentes ausentes: o mecanismo normal do fechamento do espaço entre os incisivos centrais recentemente erup- cionados depende dos incisivos laterais e suas relaçōes de mudança com as raízes, o colo e coroa dos incisivos centrais, nesta ordem. Quando os incisivos laterais são congenitamente ausentes, é freqüente uma relaçăo axial diferente dos incisivos centrais, um em relaçāo ao outro, sendo seus longos eixos paralelos ou mesmo divergentes a medida que progridem apicalmente. Sem germes dentários dos incisivos laterais eles tendem a se espalhar lateralmente. $(01,02)$.

2.c. Incisivos laterais conóides: na erupçăo dos incisivos laterais conóides (ou qualquer outra forma de microdontia) que ocupam um pequeno espaço mésio distal, há um fechamento parcial do diastema, de forma normal, mas em menor grau em relaçăo a um dente de tamanho normal. $(01,02,35)$.

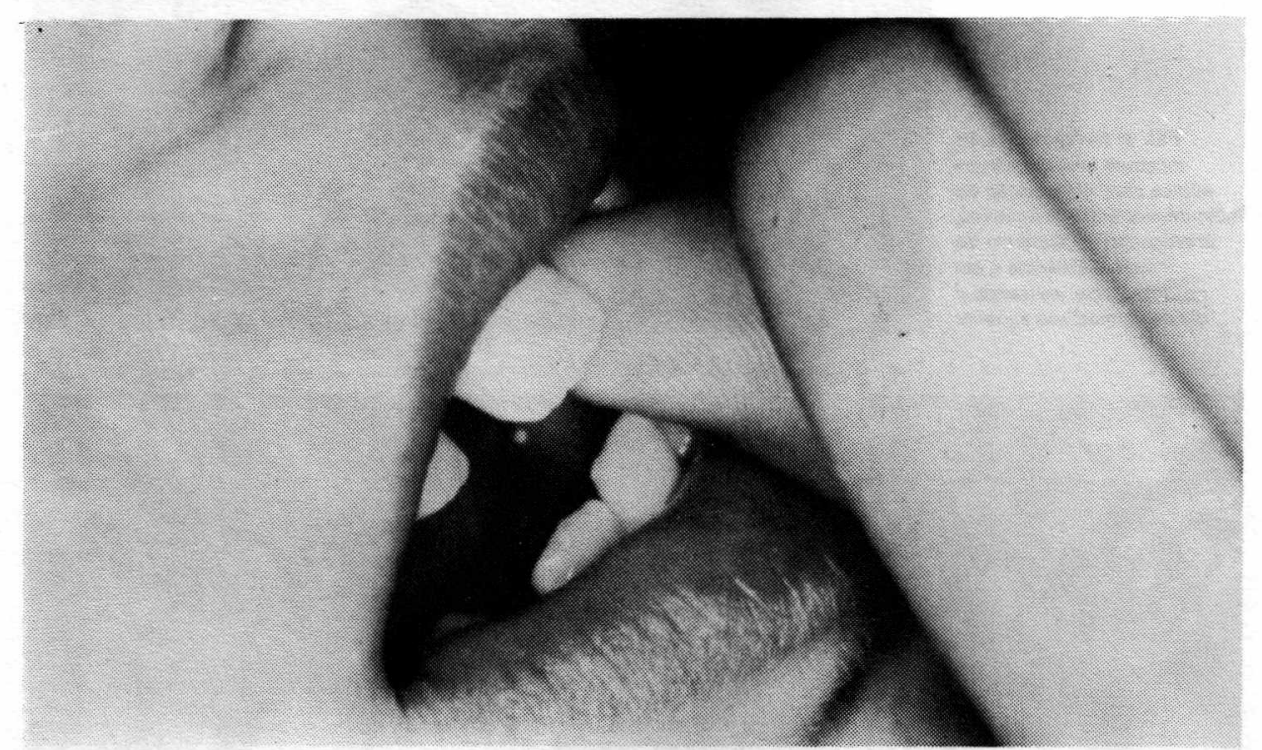

FIG. 7: As figuras 7 e 8 mostram um hábito de sucção de polegar e o consequente diastema causado por esse hábito

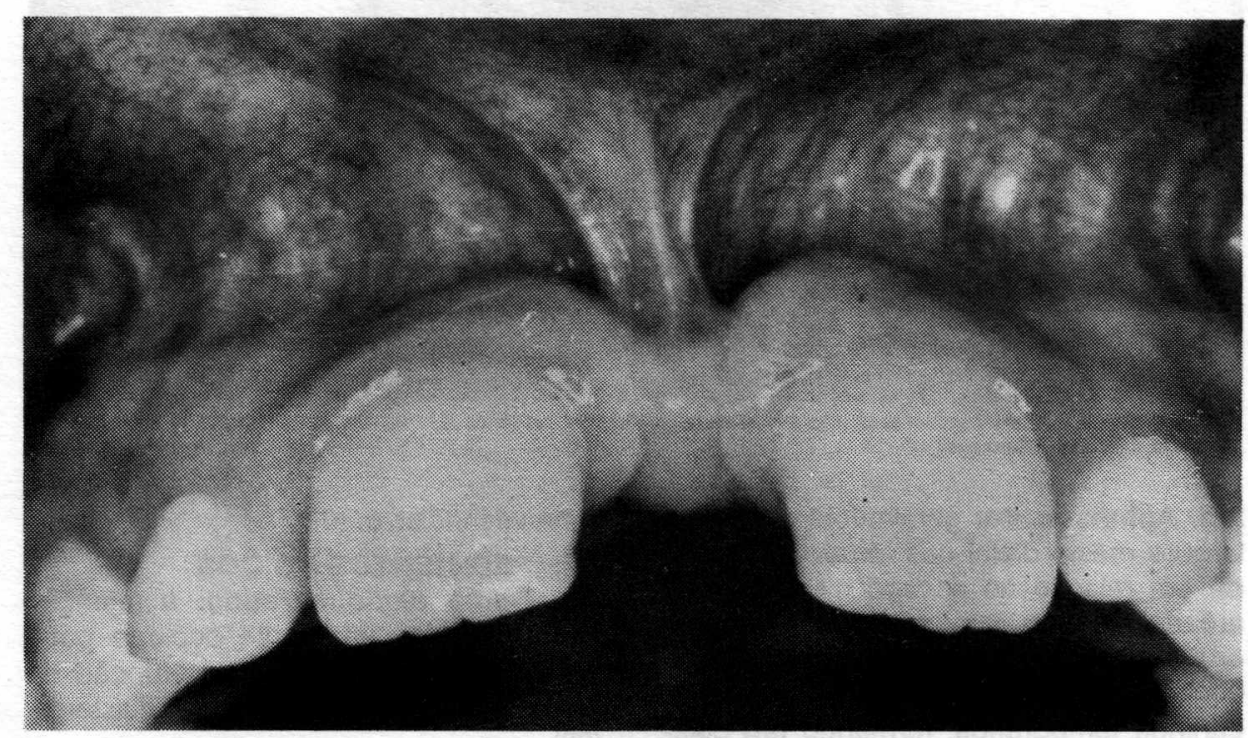

2.d. Dentes ectópicos: o germe de um dente que está irrompendo ectopicamente não pode assumir seu próprio papel na seqüência dos movimentos que levam ao fechamento do diastema $e$ ao alinhamento espontâneo dos dentes anteriores. Os dentes deslocados năo oferecem pressāo distal nos incisivos centrais para guiar o fechamento. (02).

2.e. Dentes extraídos: a quebra da integridade de uma arcada completa, causada por uma extração pode ser a causa da reabertura do espaço da linha média (ou qualquer outro lugar).

2.f. Comprimento de arco aumentado: alguns hábitos como sucçāo de polegar, interposição de língua e/ou lábio podem ocasionar um aumento da sobressaliência, pois aumenta o comprimento local do osso alveolar. $(02,35)$. Figs. $7,8,9,10 \mathrm{e}$ 11.
R. Fac. Odontol.

Porto Alegre

V. 32

N. 2

p.9-14

NOVEMBRO 

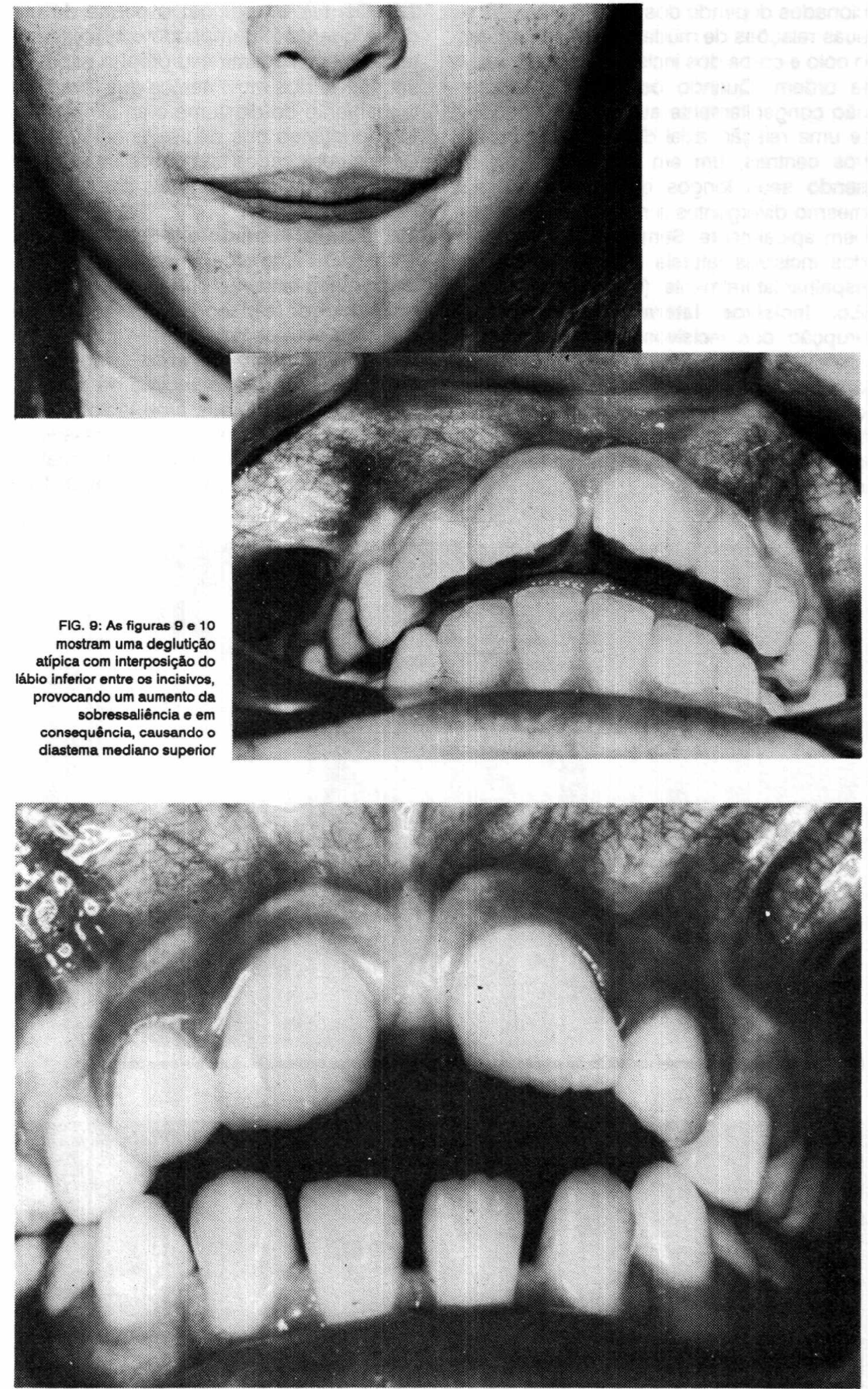

FIG. 11: Diastema mediano superior associado à mordida aberta anterior, causados por deglutição atípica, com interposição de lingua entre os dentes anteriores

2.g. Apinhamento: geralmente quando a largura mésio distal dos incisivos é grande em relação ao espaço disponível na arcada, os incisivos laterais permanentes erupcionam palatinamente e os incisivos centrais permanentes se aproximam dos caninos temporários, formando um dias-

\section{IMPEDIMENTOS FÍSICOS}

3.a. Dente decíduo retido: a retenção prolongada de um dente decíduo pode provocar desvio do eixo de erupção do dente permanente, causando diastema. (02). 3.b. Dentes supranumerários: a zona de maior incidência de dentes supranumerários é a área da linha média, como o mésio, impedindo a uniảo dos incisivos centrais permanentes, provocando diastema. (02).

3.c. Freio labial aumentado: um diastema pode ser causado por um freio realmente patológico, chamado freio teto labial persisitente, agindo como um impedimento físico para a aproximaçāo dos incisivos superiores. Porém a incidência deste freio é baixa na populaçăo. (02).

3.d. Outras patologias da linha média: cistos, tumores, e outras patologias da linha média podem existir e provocar um diastema. (02).

\section{CAUSAS ARTIFICIAIS}

4.a. Expansão palatal rápida: o tratamento para uma mordida cruzada posterior bilateral pode envolver forças ortopédicas, ao invés de ortodônticas, para abrir a sutura da linha média e mover as metades separadas do arco superior para uma relaçāo mais normal com o interior. Essa disjunçāo é feita através de aparelhos fixos e provoca uma acentuada separaçăo entre os incisivos centrais. (02).

4.b. Suporte de Milwaukee: algumas vezes usado no tratamento da escoliose da coluna vertebral. Este aparelho, quando usado por tempo prolongado, tende a separar os incisivos superiores, pois produz uma tensāo progressiva da arcada inferior contra a superior, causando diastemas. (02).

\section{CARACTERÍSTICAS DO FREIO ANORMAL}

Sem dúvida, o freio labial persistente 6 um agente etiológico do diastema superior, porém ele deve ser corretamente diagnosticado para que nâo se façam ressecçōes desnecessárias.

O freio anormal apresenta uma forma triangular bem maior que a do freio normal, ligado ao lábio superior, e afila em direçāo para baixo se estendendo entre os incisivos centrais para uma união definitiva com a papila palatina. $(02,05,07,08)$.

Parece se tornar mais pronunciado a medida que a criança cresce, ao contrário dos freios ditos normais.

Podemos examinar distendendo o lábio superior para fora e para cima. Se esta tensão aplicada intermitentemente produz isquemia $\theta$ uma quantidade definitiva de movimentos, năo somente dos tecidos moles, mas também das papilas palatina e interincisiva, passando entre os incisivos centrais superiores, o freio pode ser considerado anormal. (08). Figs. 12, 13 e 14. 


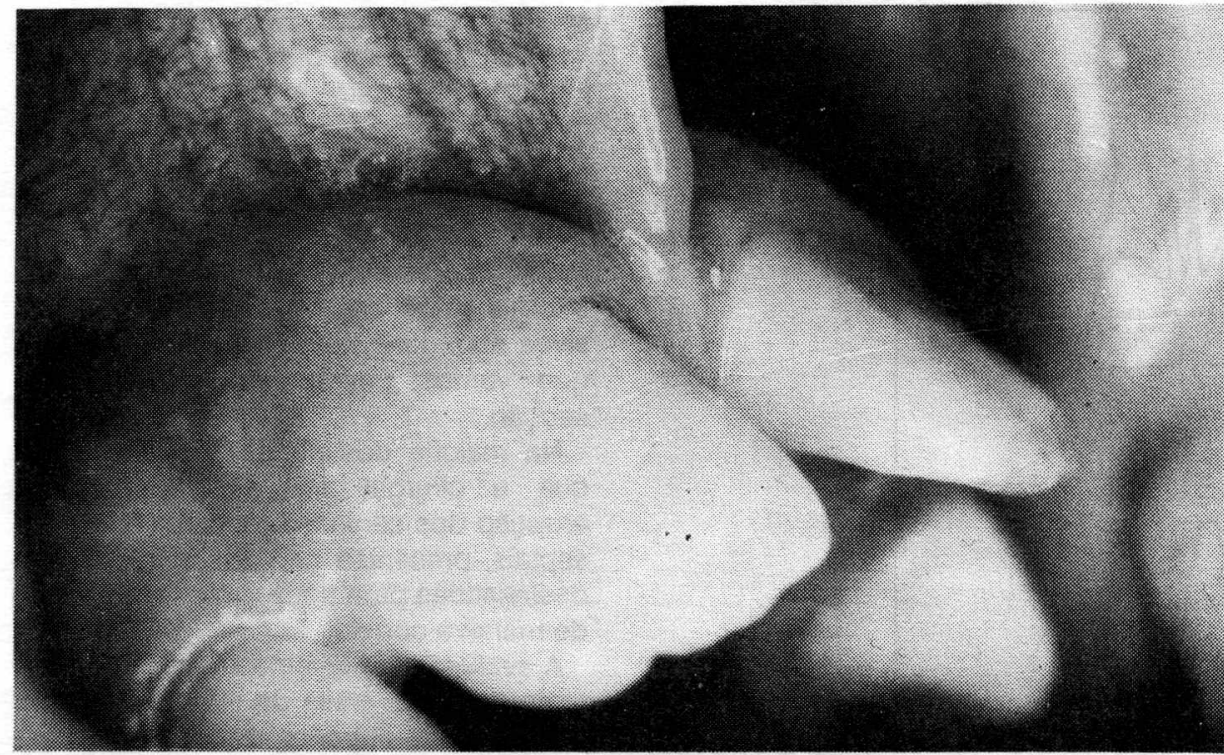

FIG. 12: As figuras 12, 13 e 14 mostram a sequência do exame clínico no diagnóstico do freio teto-labial persistente. Ao tracionarmos o lábio superior para cima e para frente, ocorre uma isquemia e uma quantidade definida de movimentos, nâo somente dos tecidos moles entre os incisivos centrais, mas também das papilas palatina e interincisiva
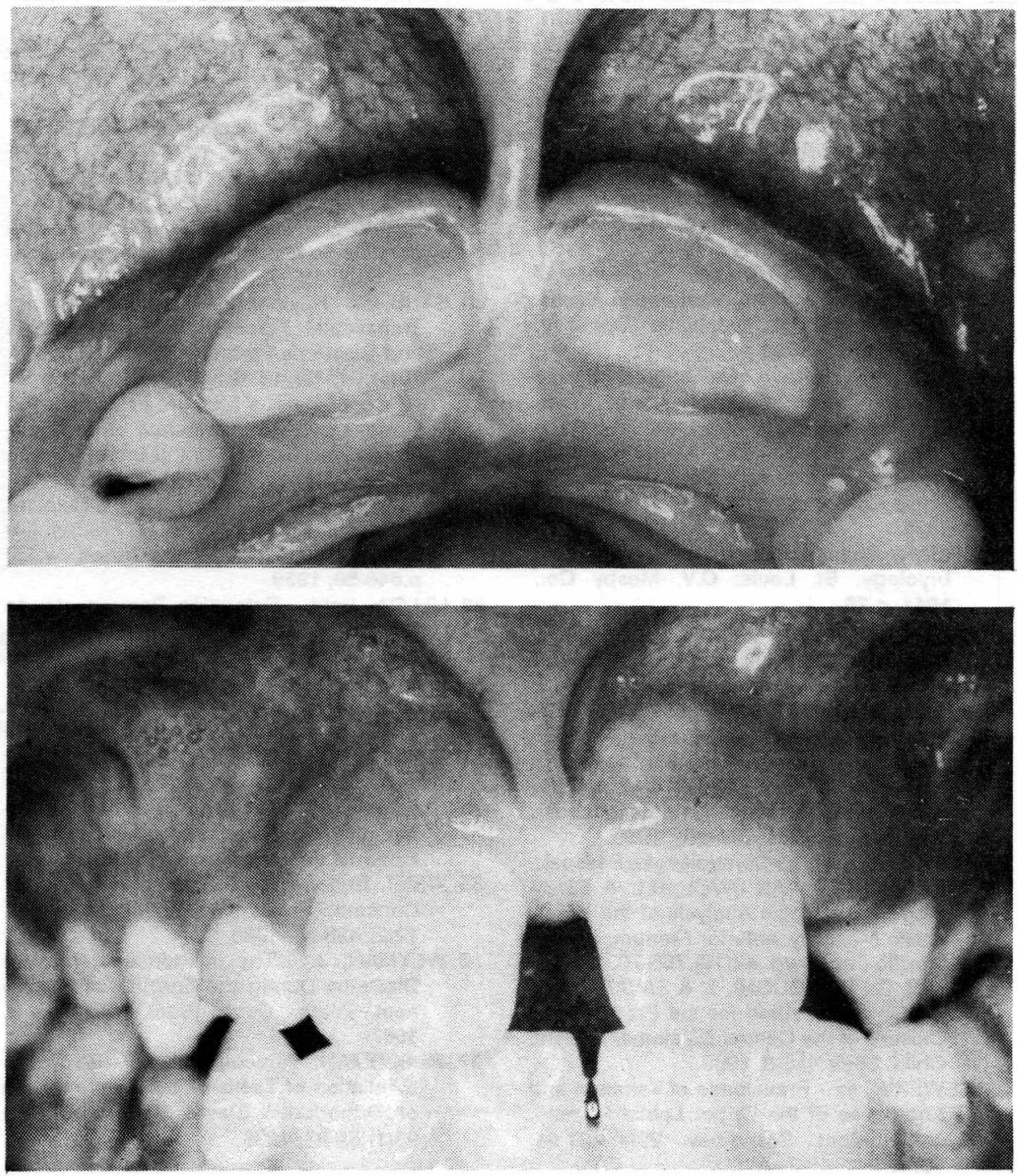

Popovich (20), em 1977, sugeriu uma seqüência de diagnóstico onde:

1. Se deve registrar a anamnese do paciente da familia.

2. Observar o desenvolvimento dentário ou a maturação (sendo que idade cronológica nem sempre é indicaçảo de idade biológica). Se o diastema não fechar até os 12 anos (aproximadamente), provavelmente permanecerá.

3. Radiografar a regiảo para excluir patologias na linha média ou ausências congênitas de dentes.

4. Medir as proporçōes entre os dentes e os arcos.

5. Examinar os tipos de sutura associado aos tipos de freio.

Para melhor analisarmos a seqüência acima, Popovich definiu 4 tipos de sutura quanto ao aspecto radiográfico.

1. Osso em forma de "V", cortado por uma sutura interproximal.

2. Osso normal com sutura larga e pouco profunda.

3. Osso em forma de pá.

4. Osso em forma de "W", com sutura profunda. Figs. 15 e 16.

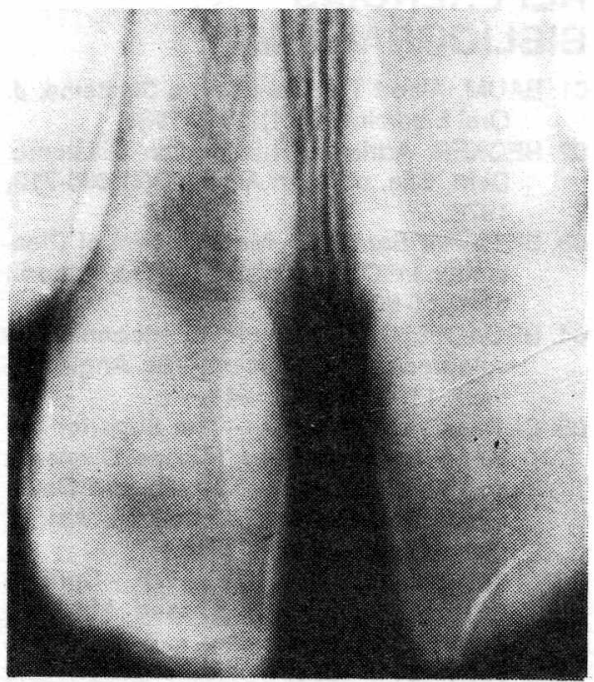

FIG. 15: Imagem radiográfica da sutura palatina mediana do caso mostrado nas figuras 12,13 e 14 . Observa-se um osso em forma de "V" com uma profunda sutura intermaxilar

Definiu, também, 6 tipos de freios com relaçảo a sua inserçăo e espessura.
1. Alto e fino.
2. Alto e grosso.
4. Médio e grosso.
3. Médio e fino.
5. Baixo e fino.
6. Baixo e grosso.

Popovich concluiu que o freio teto labial persistente está associado a combinação de imagem radiográfica 3 e 4 , e tipos de freios 5 e 6 .

\section{CONCLUSÃO}

Uma das principais características do desenvolvimento do freio é a variabilidade em forma, tamanho e posição na mesma pessoa em idadees diferentes e em pes-

R. Fac. Odontol.

N. 2

p.9-14 NOVEMBRO 


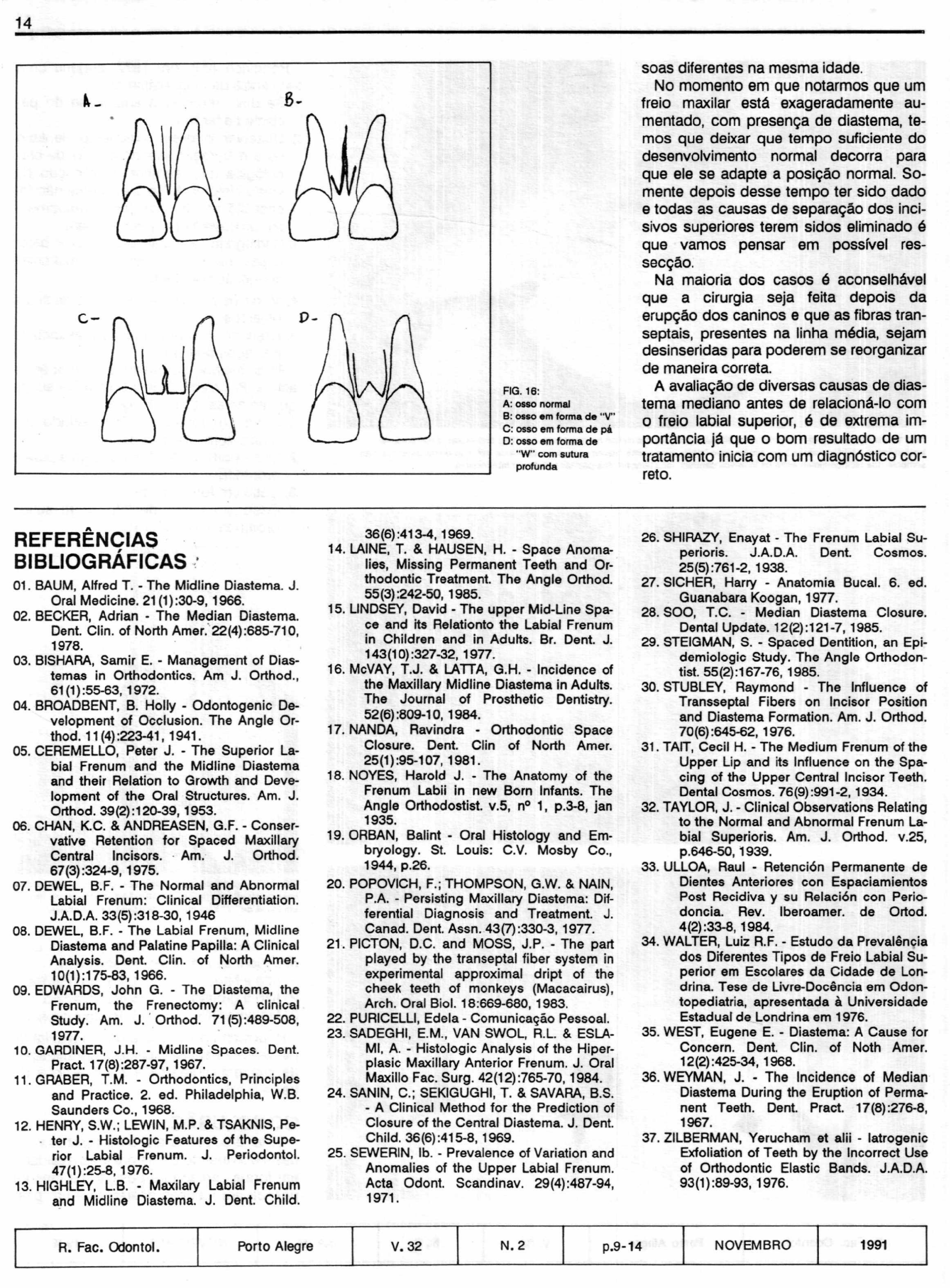

